\title{
Density, Viscosity, and Surface and Interfacial Tensions of Mixtures of Water $+n$-Butyl Acetate + 1-Propanol at 303.15 K and Atmospheric Pressure
}

\author{
I. Johnson • H. F. Costa • A. G. M. Ferreira • \\ I. M. A. Fonseca
}

Received: 18 June 2007 / Accepted: 28 March 2008 / Published online: 26 April 2008

(C) Springer Science+Business Media, LLC 2008

\begin{abstract}
Experimental densities, viscosities, and surface and interfacial tensions have been measured at $303.15 \mathrm{~K}$ for liquid mixtures of water $+n$-butyl acetate + 1-propanol. The excess molar volume, $V^{\mathrm{E}}$, viscosity, $\eta$, and surface tension, $\gamma$, were calculated and rational functions due to Myers and Scott, and Pando et al. were used to describe the composition dependence of these properties. The viscosity, $\eta$, of the mixtures was correlated using a theoretically based method developed from the Eyring theory using the above-mentioned rational functions to express the excess Gibbs energy of activation for viscous flow, $G^{\neq \mathrm{E}}$. The UNIMOD model based on the Eyring theory was used to correlate the viscosity of the binaries and to predict the same property for ternary mixtures. To describe the above-mentioned properties of the ternary system, binary pair additivity and some empirical models were considered. The methods of Fu et al. and Li et al. were used to correlate the binary surface tension and also to predict the ternary behavior. The interfacial tension was correlated by the $\mathrm{Li}$ and $\mathrm{Fu}$ method.
\end{abstract}

Keywords Density $\cdot$ Interfacial tension $\cdot n$-Butyl acetate $\cdot 1$-Propanol · Surface tension · Viscosity $\cdot$ Water

\section{Introduction}

Extensive information on the thermodynamic and transport properties of water+ alkanol liquid mixtures and their binary subsystems are needed in multiple industrial

\footnotetext{
I. Johnson

Department of Physics, St. Joseph's College, Trichy, 620002, India

H. F. Costa · A. G. M. Ferreira · I. M. A. Fonseca $(\varangle)$

Departamento de Engenharia Química, Universidade de Coimbra, Pólo II, Pinhal de Marrocos,

Coimbra 3030-290, Portugal

e-mail: fonseca@eq.uc.pt
} 
processes such as fluid flow, heat and mass transfer, and also for the development of theoretical research on molecular interactions in solutions. A knowledge of the density, viscosity, and surface and interfacial tensions of aqueous systems containing aliphatic esters is essential in many fields, such as the food, and the flavor and flagrance industries.

The alkanol + alkanoate systems are of great interest from a theoretical point of view since in mixing processes the breaking of $\mathrm{H}$-bonded structures of the alcohol occurs and the formation of new H-bonded molecular species between the alcohol and the ester takes place [1]. Ternary mixtures are the simplest multicomponent system to treat experimentally and to provide the appropriate basis for the application of correlation and prediction models.

The present work is part of a research program which has been developed in our laboratory to provide density, viscosity, and surface and interfacial tensions for water + ester + alcohol at different temperatures [2-5]. These systems show liquidliquid immiscibility, with the water + alkanoate system practically immiscible over the complete composition range. Recently, we measured the densities of the pure esters over wide ranges of temperature and pressure [6].

We report in this article the density, $\rho$, the dynamic viscosity, $\eta$, and the surface tension, $\gamma$, for ternary mixtures of water $+n$-butyl acetate +1 -propanol and its binary constituents at $303.15 \mathrm{~K}$ and atmospheric pressure. The interfacial tension, $\gamma^{\prime}$, was also measured in the liquid-liquid immiscibility domain. The rational functions proposed by Myers and Scott [7] and Pando et al. [8] have been applied to correlate the measured properties.

The statistical mechanical theory of reaction rate developed by Eyring has been used to correlate the viscosity [9]. This theory describes the motion of molecules in the way of a chemical reaction. When a molecule moves from one position to another in the liquid, it should possess higher energy than the neighboring molecules in order to produce a hole and move to an available position. The extra energy is the activation energy for the flow. The application of the Eyring theory to mixtures following these ideas leads to the concept of the excess Gibbs energy of activation of viscous flow [9], which has been used to correlate the viscosity and to predict this property for ternary mixtures.

Some other methods have been used for correlation and prediction of viscosity. The model of Noda and Ishida [10] was applied for the correlation of binary viscosity data; and the UNIMOD model, due to Cao etal. [11,12], was also applied as a correlation model and also to predict the viscosity of multicomponent mixtures from a knowledge of binary interaction parameters.

The surface-tension data of binary mixtures were correlated with the models of $\mathrm{Fu}$ et al. [13] and Li et al. [14]. The same models were applied for the prediction of ternary data. The liquid interfacial tension data were correlated with a relation proposed by $\mathrm{Li}$ and $\mathrm{Fu}[15]$.

\section{Experimental}

Tri-distilled water was used. 1-Propanol (Riedel de Häen) was supplied with a mass fraction purity better than 0.995. $n$-Butyl acetate was supplied by Sigma-Aldrich with 
a stated purity better than 0.995 . The purity of the chemicals was checked by measuring their density, viscosity, and surface tension. The properties of the three components together with values found in the literature are presented in Table 1.

The liquid mixtures were prepared by mass using a Mettler AT 200 balance with a precision of $\pm 1 \times 10^{-5} \mathrm{~g}$. The uncertainty of the mole fraction is estimated to be of the order $\pm 1 \times 10^{-4}$.

Densities were measured with an Anton Paar DMA 60 digital vibrating-tube densimeter, with a DMA 602 measuring cell. Air and pure water were used for calibration of the densimeter. The temperature control was performed using an UltraTerm $\mathrm{P}$ Selecta thermostatic water bath, with a temperature uncertainty of $\pm 0.01 \mathrm{~K}$. For the case of density measurements, a Pt resistance thermometer (calibrated against a standard mercury thermometer, graduated in $0.01 \mathrm{~K}$, certified by NPL, UK) was placed inside the vibrating-tube densimeter to find the actual temperature of the measurements. The temperature was maintained at $(303.15 \pm 0.01) \mathrm{K}$.

Kinematic viscosities, $v$, of pure components and their binary and ternary mixtures were determined by using an Ubbelohde viscometer with a Schott-Geräte automatic measuring unit (Model AVS-470), for which the uncertainty in the flow time of measurement is $\pm 0.01 \mathrm{~s}$. A thermostatically controlled bath was used for which the temperature was monitored by a digital thermometer with an uncertainty of $\pm 0.01 \mathrm{~K}$. The viscometer constant was checked with pure compounds (methanol and 1-propanol) from 298.15 to $323.15 \mathrm{~K}$. Kinetic-energy corrections were applied to the experimental data.

Surface and interfacial tensions were measured using a PC controlled KSV Sigma 70 tension balance which employs the Du Noüy ring-detachment method. The platinum ring was thoroughly cleaned by immersion in a concentrated solution of nitric acid for several hours. Then it was rinsed with acetone, carefully flamed in a Bunsen burner, washed again with acetone, and dried. The measurements were automatically corrected to the actual values by means of the Huh and Mason compensation for interface distortion. The temperature inside the surface tension measurement vessel was maintained and controlled at $(303.15 \pm 0.01) \mathrm{K}$ using an UltraTerm P Selecta bath.

For the liquid interfacial-tension measurements, mixtures with a known global composition were kept at $303.15 \mathrm{~K}$ in a thermostated vessel and shaken several times during a period of at least $24 \mathrm{~h}$ to reach equilibrium.

Table 1 Densities, $\rho$, viscosities, $\eta$, and surface tensions, $\gamma$ of the pure components at $303.15 \mathrm{~K}$

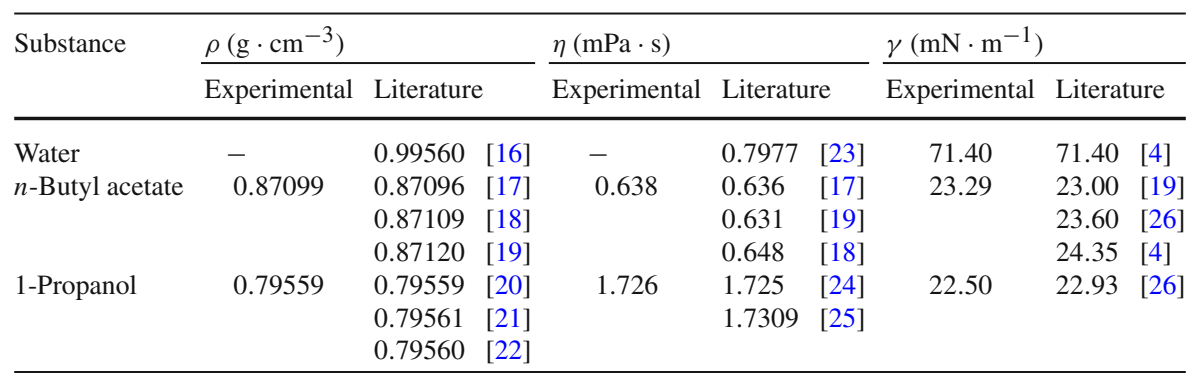


The measurement of viscosity and surface tension was accomplished using the following methodology. A binary mixture was used as a starting point of measurements for the water (1) + 1-propanol (3) or $n$-butyl acetate (2) + 1-propanol (3) systems. The ternary data were obtained following lines of constant mole fraction ratios of $z=x_{1} / x_{3}$ and $z=x_{2} / x_{3}$, respectively.

Densities were measured with an uncertainty of $\pm 1 \times 10^{-5} \mathrm{~g} \cdot \mathrm{cm}^{-3}$. Having in mind that the error in the excess molar volume, $V^{\mathrm{E}}$, is determined by the uncertainties in mole fraction and density, the maximum error in $V^{\mathrm{E}}$ resulting from the propagation of errors is $\pm 1 \times 10^{-3} \mathrm{~cm}^{3} \cdot \mathrm{mol}^{-1}$. Taking into consideration the uncertainties in the measured time and density, the estimated experimental uncertainty in the viscosity is $\pm 1 \times 10^{-3} \mathrm{mPa} \cdot \mathrm{s}$.

The precision of the surface tension is indicated by the instruction manual of the tension balance as $\pm 0.01 \mathrm{mN} \cdot \mathrm{m}^{-1}$. Each experimental point results from a set of about 20 measurements. After the first few measurements, the measurements attain a practically constant value.

\section{Results}

In Table 2 experimental density data are presented and in Table 3 we show the values of viscosity and surface tension for the ternary system and constituent binaries at $303.15 \mathrm{~K}$ as a function of the composition.

The calculation of the dynamic viscosity, $\eta=\rho v$, is done by using

$$
v=k(t-\theta)
$$

where $\rho$ is the density of the mixture, $v$ is the kinematic viscosity, $k$ is the viscometer constant, $t$ is the flow time, and $\theta$ is the kinetic-energy correction factor (HagenbachCouette correction) whose value is given by the manufacturer and depends on the flow time.

The viscosity and surface-tension measurements were made for different compositions than those of the density, since they were not performed simultaneously. For that reason, the density value needed to obtain the dynamic viscosity was calculated with a fitted equation for $V^{\mathrm{E}}$.

In Table 4 the experimental liquid interfacial tension, $\gamma^{\prime}$, is listed for the ternary system. In this table the surface tension, $\gamma$, and the compositions of the liquid phases at equilibrium are also presented. The composition of the liquid phases at equilibrium was determined using the tie-line data from Rao and Rao [27].

\section{Correlation and Prediction}

The excess molar volumes, $V^{\mathrm{E}}$, were obtained from the measured density by the expression,

$$
V^{\mathrm{E}}=\rho^{-1}\left(\sum_{i=1}^{c} x_{i} M_{i}\right)-\sum_{i=1}^{c} x_{i} M_{i} \rho_{i}^{-1}
$$


Table 2 Experimental densities, $\rho$, for the water (1) + $n$-butyl acetate (2) +1-propanol (3) system and its binary constituents at $303.15 \mathrm{~K}$ and atmospheric pressure

\begin{tabular}{|c|c|c|c|c|c|}
\hline$x_{1}$ & $x_{2}$ & $\rho\left(\mathrm{g} \cdot \mathrm{cm}^{-3}\right)$ & $x_{1}$ & $x_{2}$ & $\rho\left(\mathrm{g} \cdot \mathrm{cm}^{-3}\right)$ \\
\hline 0.0202 & 0.9798 & 0.87186 & 0.4476 & 0.0181 & 0.84071 \\
\hline 0.0407 & 0.9593 & 0.87230 & 0.4387 & 0.0376 & 0.84200 \\
\hline 0.0635 & 0.9365 & 0.87281 & 0.2659 & 0.0216 & 0.82076 \\
\hline 0.9677 & 0 & 0.98044 & 0.2109 & 0.4316 & 0.85476 \\
\hline 0.9304 & 0 & 0.96195 & 0.2190 & 0.3413 & 0.84857 \\
\hline 0.8862 & 0 & 0.94198 & 0.3436 & 0.2868 & 0.85660 \\
\hline 0.8334 & 0 & 0.92207 & 0.1896 & 0.2767 & 0.84034 \\
\hline 0.7699 & 0 & 0.90165 & 0.3281 & 0.2294 & 0.84975 \\
\hline 0.6896 & 0 & 0.88039 & 0.4368 & 0.1923 & 0.85880 \\
\hline 0.5885 & 0 & 0.85970 & 0.1797 & 0.2111 & 0.83340 \\
\hline 0.4558 & 0 & 0.83949 & 0.3147 & 0.1764 & 0.84313 \\
\hline 0.3589 & 0 & 0.82752 & 0.4215 & 0.1489 & 0.85250 \\
\hline 0.2444 & 0 & 0.81593 & 0.5087 & 0.1265 & 0.86167 \\
\hline 0.1440 & 0 & 0.80710 & 0.1726 & 0.1501 & 0.82684 \\
\hline 0.2718 & 0 & 0.81854 & 0.3018 & 0.1266 & 0.83672 \\
\hline 0 & 0.8999 & 0.86611 & 0.4096 & 0.1071 & 0.84668 \\
\hline 0 & 0.7993 & 0.86078 & 0.1630 & 0.0958 & 0.82013 \\
\hline 0 & 0.7000 & 0.85520 & 0.2901 & 0.0813 & 0.83042 \\
\hline 0 & 0.5999 & 0.84892 & 0.1920 & 0.0441 & 0.81675 \\
\hline 0 & 0.5002 & 0.84231 & 0.0695 & 0.1188 & 0.81497 \\
\hline 0 & 0.3999 & 0.83507 & 0.1121 & 0.2333 & 0.82989 \\
\hline 0 & 0.3000 & 0.82708 & 0.0831 & 0.3530 & 0.83778 \\
\hline 0 & 0.2001 & 0.81793 & 0.1182 & 0.4504 & 0.84810 \\
\hline 0 & 0.1000 & 0.80765 & 0.0535 & 0.5594 & 0.85044 \\
\hline 0.8238 & 0.0116 & 0.91895 & 0.1645 & 0.5453 & 0.85861 \\
\hline 0.7604 & 0.0123 & 0.89966 & 0.0860 & 0.6465 & 0.85858 \\
\hline 0.7499 & 0.0246 & 0.89775 & 0.1020 & 0.7382 & 0.86520 \\
\hline 0.6801 & 0.0137 & 0.87975 & 0.0210 & 0.8732 & 0.86635 \\
\hline 0.6697 & 0.0289 & 0.87906 & 0.0597 & 0.7005 & 0.85971 \\
\hline 0.6586 & 0.0450 & 0.87850 & 0.0400 & 0.8196 & 0.86494 \\
\hline 0.6464 & 0.0627 & 0.87783 & 0.0972 & 0.3499 & 0.83866 \\
\hline 0.5792 & 0.0158 & 0.86023 & 0.0498 & 0.3490 & 0.83479 \\
\hline 0.5692 & 0.0327 & 0.86060 & 0.0800 & 0.1999 & 0.82406 \\
\hline 0.5585 & 0.0509 & 0.86100 & & & \\
\hline
\end{tabular}

where $x_{i}, M_{i}$, and $\rho_{i}$ are the mole fraction, the molar mass, and the measured density of the pure component $i$, respectively. $c$ is the number of species.

The reaction rate theory of Eyring was assumed to hold and used to correlate the viscosity data. According to this theory [9], the viscosity, $\eta_{i}$, of a pure liquid $i$ is

$$
\eta_{i}=\frac{N_{\mathrm{A}} h}{V_{i}} \exp \left(\frac{G_{i}^{\neq}}{R T}\right)
$$

where $h$ is Plank's constant, $N_{\mathrm{A}}$ is the Avogadro number, $G_{i}^{\neq}$is the Gibbs energy of activation of viscous flow of pure liquid $i$, and $T$ is the temperature. For a mixture the following equation is derived: 
Table 3 Experimental viscosities, $\eta$, and surface tensions, $\gamma$, for the water $(1)+n$-butyl acetate (2)+ 1-propanol (3) system and its binary constituents at $303.15 \mathrm{~K}$ and atmospheric pressure

\begin{tabular}{|c|c|c|c|c|c|c|c|}
\hline$x_{1}$ & $x_{2}$ & $\eta(\mathrm{mPa} \cdot \mathrm{s})$ & $\gamma\left(\mathrm{mN} \cdot \mathrm{m}^{-1}\right)$ & $x_{1}$ & $x_{2}$ & $\eta(\mathrm{mPa} \cdot \mathrm{s})$ & $\gamma\left(\mathrm{mN} \cdot \mathrm{m}^{-1}\right)$ \\
\hline 0.0190 & 0.9810 & & 23.75 & 0.0333 & 0.6667 & 0.690 & 23.37 \\
\hline 0.0290 & 0.9710 & & 23.79 & 0.0222 & 0.7779 & 0.662 & 23.35 \\
\hline 0.0340 & 0.9660 & & 23.85 & 0.0110 & 0.8890 & 0.643 & 23.32 \\
\hline 0.0400 & 0.9600 & 0.641 & 23.90 & 0.1751 & 0.1249 & 1.334 & 23.50 \\
\hline 0.0510 & 0.9490 & & 24.01 & 0.1500 & 0.2500 & 1.050 & 23.79 \\
\hline 0.0599 & 0.9401 & 0.639 & & 0.1250 & 0.3751 & 0.876 & 23.90 \\
\hline 0.0201 & 0.9799 & 0.640 & & 0.1001 & 0.4999 & 0.782 & 23.80 \\
\hline 0.0998 & 0 & 1.794 & 23.54 & 0.0750 & 0.6250 & 0.737 & 23.69 \\
\hline 0.2000 & 0 & 1.852 & 24.20 & 0.0500 & 0.7502 & 0.693 & 23.59 \\
\hline 0.2998 & 0 & 1.940 & 25.03 & 0.0250 & 0.8750 & 0.646 & 23.49 \\
\hline 0.3999 & 0 & 2.065 & 25.77 & 0.2571 & 0.1429 & 1.328 & 23.01 \\
\hline 0.5001 & 0 & 2.135 & 26.41 & 0.2400 & 0.2000 & 1.143 & 23.22 \\
\hline 0.5998 & 0 & 2.226 & 26.75 & 0.2143 & 0.2857 & 0.972 & 23.05 \\
\hline 0.6996 & 0 & 2.273 & 27.35 & 0.1714 & 0.4286 & 0.860 & 23.86 \\
\hline 0.7953 & 0 & 2.212 & 27.96 & 0.1286 & 0.5714 & 0.721 & 24.16 \\
\hline 0.8498 & 0 & & 28.14 & 0.0857 & 0.7143 & 0.664 & 23.94 \\
\hline 0.8997 & 0 & 1.795 & 28.38 & 0.0429 & 0.8571 & 0.646 & 23.73 \\
\hline 0.9201 & 0 & & 30.07 & 0.3600 & 0.1000 & 1.529 & 23.58 \\
\hline 0.9401 & 0 & 1.463 & 32.10 & 0.3333 & 0.1667 & 1.300 & 22.83 \\
\hline 0.9596 & 0 & & 35.76 & 0.2667 & 0.3333 & 0.913 & 24.27 \\
\hline 0.9800 & 0 & 1.025 & 46.66 & 0.2000 & 0.5000 & 0.799 & 24.71 \\
\hline 0 & 0.1003 & 1.296 & 22.75 & 0.1333 & 0.6667 & 0.713 & 24.35 \\
\hline 0 & 0.1980 & 1.062 & 22.95 & 0.0667 & 0.8333 & 0.658 & 24.00 \\
\hline 0 & 0.3002 & 0.912 & 23.11 & 0.4500 & 0.1000 & 1.585 & 22.97 \\
\hline 0 & 0.4004 & 0.821 & 23.24 & 0.4000 & 0.2000 & 1.262 & \\
\hline 0 & 0.5001 & 0.755 & 23.33 & 0.3500 & 0.3000 & 0.973 & \\
\hline 0 & 0.6002 & 0.705 & 23.39 & 0.5700 & 0.0500 & 1.901 & 24.01 \\
\hline 0 & 0.7001 & 0.674 & 23.42 & 0.5400 & 0.1000 & 1.658 & 23.33 \\
\hline 0 & 0.7999 & 0.654 & 23.41 & 0.4001 & 0.0600 & 1.714 & 25.00 \\
\hline 0 & 0.9002 & 0.641 & 23.37 & 0.4998 & 0.0501 & 1.836 & 25.57 \\
\hline 0.0888 & 0.1111 & 1.320 & 23.51 & 0.6002 & 0.0400 & 1.985 & 26.13 \\
\hline 0.0778 & 0.2222 & 1.071 & 23.48 & 0.7000 & 0.0302 & 2.105 & 27.37 \\
\hline 0.0666 & 0.3334 & 0.882 & 23.46 & 0.2001 & 0.1600 & 1.260 & 24.16 \\
\hline 0.0556 & 0.4445 & 0.805 & 23.43 & 0.3002 & 0.1401 & 1.359 & 24.68 \\
\hline 0.0501 & 0.5000 & 0.768 & 23.41 & 0.4000 & 0.1200 & 1.509 & 25.21 \\
\hline 0.0445 & 0.5554 & 0.737 & 23.40 & 0.5002 & 0.1001 & 1.574 & 26.45 \\
\hline
\end{tabular}

Table 4 Experimental liquid interfacial tension, $\gamma^{\prime}$, for the water $(1)+n$-butyl acetate (2) +1 -propanol (3) ternary system at $303.15 \mathrm{~K}$ and atmospheric pressure

\begin{tabular}{|c|c|c|c|c|c|c|c|c|}
\hline \multicolumn{2}{|c|}{ Overall composition } & \multicolumn{3}{|c|}{ Water layer } & \multicolumn{3}{|c|}{ Organic layer } & \multirow[t]{2}{*}{$\gamma^{\prime}\left(\mathrm{mN} \cdot \mathrm{m}^{-1}\right)$} \\
\hline$z_{1}$ & $z_{3}$ & $x_{1}$ & $x_{3}$ & $\gamma\left(\mathrm{mN} \cdot \mathrm{m}^{-1}\right)$ & $x_{1}$ & $x_{3}$ & $\gamma\left(\mathrm{mN} \cdot \mathrm{m}^{-1}\right)$ & \\
\hline 0.850 & 0 & 0.999 & 0 & & 0.069 & 0 & & 16.20 \\
\hline 0.801 & 0.039 & 0.983 & 0.014 & 52.21 & 0.110 & 0.140 & 24.22 & 12.11 \\
\hline 0.782 & 0.080 & 0.980 & 0.017 & 49.32 & 0.210 & 0.245 & 24.13 & 9.85 \\
\hline 0.753 & 0.121 & 0.966 & 0.030 & 46.28 & 0.290 & 0.310 & 24.04 & 8.23 \\
\hline 0.695 & 0.184 & 0.961 & 0.034 & 37.14 & 0.380 & 0.340 & 23.93 & 6.10 \\
\hline 0.621 & 0.234 & 0.960 & 0.034 & 28.17 & 0.420 & 0.345 & 23.85 & 2.90 \\
\hline
\end{tabular}

The surface tension, $\gamma$, and the compositions of the liquid phases at equilibrium are also listed 


$$
\ln (\eta V)=\sum_{i=1}^{c} x_{i} \ln \left(\eta_{i} V_{i}\right)+\frac{G^{\neq \mathrm{E}}}{R T}
$$

where $V$ and $V_{i}$ are the molar volumes of the mixture and of pure component $i$ at the same pressure and temperature. $G^{\neq \mathrm{E}}$ is the excess Gibbs energy of activation of viscous flow for the mixture and can be correlated as an excess property.

The dependence of binary excess properties $X_{i j}\left(\equiv V^{\mathrm{E}}, G^{\neq \mathrm{E}}\right)$ on composition, can be described by a flexible equation proposed by Myers and Scott [7],

$$
X_{i j}=x_{i} x_{j} \frac{\sum_{k=0}^{p} B_{k} z_{i j}^{k}}{1+\sum_{l=1}^{m} C_{l} z_{i j}^{l}}
$$

where $z_{i j}=x_{i}-x_{j} . B_{k}$ and $C_{l}$ are adjustable coefficients obtained from the fitting of Eq. 5 to $V^{\mathrm{E}}$. This equation was also used to describe $G^{\neq \mathrm{E}}$ in the fitting of Eq. 4 to viscosity data.

The binary surface tension, $\gamma$, was correlated by means of the equation,

$$
\gamma=x_{i} \gamma_{i}+x_{j} \gamma_{j}+\gamma_{i j}
$$

where $\left(\gamma_{i}, \gamma_{j}\right)$ are the pure-component surface tensions and $\gamma_{i j}$ is a function given by Eq. 5 fitted to this property. For the binary viscosity, $\eta$, an expression similar to Eq. 6 was used where the function $\eta_{i j}$ was defined by Eq. 5 .

The viscosity and surface tension of the ternary mixtures have been correlated using the equations,

$$
\eta=\sum_{i=1}^{3} x_{i} \eta_{i}+\eta_{\mathrm{T}}
$$

and

$$
\gamma=\sum_{i=1}^{3} x_{i} \gamma_{i}+\gamma_{\mathrm{T}}
$$

where the properties, $\eta_{\mathrm{T}}$ and $\gamma_{\mathrm{T}}$, for the ternary systems, were calculated from the general expression,

$$
X_{\mathrm{T}}=\sum_{i<j} X_{i j}+X_{123}
$$

where $X_{i j}$ 's are functions for the same properties, obtained by fitting Eq. 5 to binary data and $X_{123}$ is a ternary contribution expressed by the Pando et al. [8] expression,

$$
X_{123}=x_{1} x_{2} x_{3}\left(\frac{B_{0}+B_{1} z_{13}+B_{2} z_{23}}{1+C_{1} z_{13}+C_{2} z_{23}}\right)
$$


This equation was also used to describe $V_{\mathrm{T}}^{\mathrm{E}}$ and $G_{\mathrm{T}}^{\neq \mathrm{E}}$, the excess molar volume and the Gibbs energy of activation of viscous flow for the ternary mixtures. The parameters of $G_{\mathrm{T}}^{\neq \mathrm{E}}$ (i.e., $G^{\neq \mathrm{E}}$ ) included in Eq. 4 were optimized using ternary viscosity data.

To correlate the viscosity, we have also used the Eyring theory. The excess Gibbs energy of activation of viscous flow for the mixture, $G^{\neq \mathrm{E}}$, which must be used in Eq. 4 can be derived from several methods. Noda and Ishida [10] proposed the following semi-empirical equation:

$$
\frac{G^{\neq \mathrm{E}}}{R T}=\sum_{j=1}^{c} x_{j} \sum_{i=1}^{c} \frac{x_{i} w_{j i}}{\sum_{k=1}^{c} x_{k} \exp \left(-w_{k i}\right)}
$$

where $w_{i i}=0$ and $w_{j i}$ and $w_{k i}$ are parameters fitted from experimental binary viscosity data using Eq. 11 inserted in Eq. 4.

Cao etal. [11,12] proposed the following equation (UNIMOD):

$$
\ln (\text { viscosity })=\sum_{i=1}^{c} \xi_{i}^{\mathrm{C}}+\sum_{i=1}^{c} \xi_{i}^{\mathrm{R}}
$$

where (viscosity) is the dynamic or the kinematic viscosity of the mixture, $\xi_{i}^{\mathrm{C}}$ is the combinatory term, and $\xi_{i}^{\mathrm{R}}$ is the residual term. For the dynamic viscosity, $\eta$, these terms are

$$
\xi_{i}^{\mathrm{C}}=\varphi_{i} \ln \left(\eta_{i} \frac{V_{i}}{V}\right)+2 \varphi_{i} \ln \left(\frac{x_{i}}{\varphi_{i}}\right)
$$

and

$$
\xi_{i}^{\mathrm{R}}=\left(-\frac{q_{i} n_{i} \varphi_{i}}{r_{i}}\right) \sum_{j=1}^{c} \theta_{j i} \ln \left(\tau_{j i}\right) .
$$

In Eq. 14, $r_{i}$ and $q_{i}$ are the number of segments and the area parameter of component $i, \theta_{i j}$ is the local composition, and $n_{i}$ is a constant. The definitions of the different composition variables are given by

$$
\begin{array}{r}
\theta_{j i}=\frac{x_{j} \tau_{j i}}{\sum_{l=1}^{c} \theta_{l} \tau_{l i}} \\
\theta_{i}=\frac{x_{i} q_{i}}{\sum_{j=1}^{c} x_{j} q_{j}}
\end{array}
$$




$$
\varphi_{i}=\frac{x_{i} r_{i}}{\sum_{j=1}^{c} x_{j} r_{j}}
$$

where $\theta_{i}$ and $\varphi_{i}$ are the area fraction and the average segment fraction of the $i$ th component and $\tau_{j i}$ is the interaction parameter between molecular sites $j$ and $i$,

$$
\tau_{j i}=\exp \left(-\frac{z}{2} \frac{U_{j i}-U_{i i}}{R T}\right)
$$

where $z$ is the coordination number given by Skjold-Jørgensen et al. [28],

$$
z=35.2-0.1272 T+0.00014 T^{2} \text {. }
$$

This model allows the prediction of the ternary viscosity from binary parameters.

To describe the surface tension, $\gamma$, the model proposed by Fu et al. [13] was used,

$$
\gamma=\sum_{i=1}^{c} \frac{x_{i} \gamma_{i}}{\sum_{j=1}^{c} x_{j} f_{i j}}-\sum_{i=1}^{c} \sum_{j=1}^{c} \frac{x_{i} x_{j}\left|\gamma_{i}-\gamma_{j}\right|}{\sum_{q=1}^{c} x_{q} f_{i q} \sum_{r=1}^{c} x_{r} f_{j r}}
$$

where the $f_{i j}$ 's are adjustable parameters for the binary systems. This equation was also used to predict the ternary surface tension.

Li et al. [14] derived the equation,

$$
\gamma=\sum_{i=1}^{c} x_{i} \gamma_{i}-R T \sum_{i=1}^{c}\left[\frac{x_{i}}{\sum_{j=1}^{c} x_{j} \Lambda_{i j}} \sum_{j}^{c} x_{j}\left(\frac{\partial \Lambda_{i j}}{\partial A}\right)_{T, P, x}\right]
$$

where

$$
\Lambda_{i j}=\exp \left(-\frac{U_{i j}-U_{i i}}{R T}\right),\left(\frac{\partial \Lambda_{i j}}{\partial A}\right)_{T, P, x}=-\frac{\Lambda_{i j}}{R T}\left[\frac{\partial\left(U_{i j}-U_{i i}\right)}{\partial A}\right]_{T, P, x}
$$

In the preceding relations, $U_{i j}-U_{i i}$ is the difference in the interaction energy between molecular pair $i j$, and the derivative $\left[\partial\left(U_{i j}-U_{i i}\right) / \partial A\right]_{T, P, x}$ reflects the energy change with the increase in surface area. In a binary system the adjustable parameters are four, i. e., $\left(U_{12}-U_{11}\right),\left(U_{21}-U_{22}\right)$, $\left[\partial\left(U_{12}-U_{11}\right) / \partial A\right]_{T, P, x}$, and $\left[\partial\left(U_{21}-U_{22}\right) / \partial A\right]_{T, P, x}$. Li et al. made the assumption $U_{i j}=\left(U_{i i}+U_{j j}\right) / 2$, reducing the number of parameters to two, i.e., $\left(U_{12}-U_{11}\right)$ and $\left[\partial\left(U_{12}-U_{11}\right) / \partial A\right]_{T, P, x}$. With the parameters in Eqs. 20 and 21 obtained from regression of the binary surface-tension data, the prediction of this property in multicomponent systems can be obtained. 
To correlate the liquid interfacial tension, the $\mathrm{Li}$ and $\mathrm{Fu}$ model [15] was used. The equation of the model is

$$
\gamma^{\prime}=\gamma_{0}^{\prime}\left(\frac{X}{X_{0}}\right)^{k}
$$

where

$$
X=-\ln \left[x_{1}^{\alpha}+x_{2}^{\beta}+x_{3 p}\right]
$$

$\gamma^{\prime}$ is the interfacial tension between the two immiscible liquid phases $\alpha$ and $\beta$ in the ternary system, and $\gamma_{0}^{\prime}$ is the interfacial tension of the partially miscible binary pair which corresponds to $x_{3}=0$ and $X=X_{0}$ in Eq. 23. $x_{1}^{\alpha}$ is the mole fraction of component 1 in the liquid phase $\alpha$ richer in component $2, x_{2}^{\beta}$ is the mole fraction of component 2 in the phase richer in component 1 , and $x_{3 \mathrm{p}}$ is the mole fraction of component 3 in the phase poor in it. Li and Fu considered the parameter $k$ as an adjustable parameter in Eq. 22, and they used a more general form,

$$
k=\sum_{i=0} k_{i} X^{i}
$$

\section{Discussion}

Table 5 presents the coefficients, $B_{k}$ and $C_{k}$ of Eq. 5 fitted to binary $V^{\mathrm{E}}, \eta$, and $\gamma$ values. The standard deviation, $\sigma$, and the average absolute deviation $(A A D)$ of the corresponding fits are also shown. In the same table the coefficients corresponding to the fitted Eq. 10 of the ternary data are presented. The $\sigma$ and the $A A D$ of the fits are defined as usual;

$$
\sigma=\left[\sum_{i=1}^{N} \frac{\left(X_{\mathrm{calc}}-X_{\mathrm{exp}}\right)_{i}^{2}}{N-n}\right]^{1 / 2}
$$

and

$$
A A D=\frac{100}{N}\left[\sum_{i=1}^{N}\left|\left(X_{\text {calc }}^{\mathrm{E}}-X_{\exp }^{\mathrm{E}}\right) / X_{\text {exp }}^{\mathrm{E}}\right|_{i}\right]
$$

where $X\left(\equiv V^{E}, \eta, \gamma\right)$ and the subscripts calc and exp refer to calculated and experimental values and $N$ and $n$ represent the number of experimental points and parameters, respectively.

In Fig. 1 we have plotted the experimental $V^{\mathrm{E}}$ for the binary systems, water+ 1-propanol and $n$-butyl acetate +1 -propanol, as a function of the composition of water 
Table 5 Coefficients of Eqs. 5 and 10 fitted to the excess molar volumes, $V^{\mathrm{E}}$, viscosity, $\eta$, and surface tension, $\gamma$, for the binary and ternary systems

\begin{tabular}{|c|c|c|c|c|c|c|c|}
\hline System & $B_{0}$ & $B_{1}$ & $B_{2}$ & $C_{1}$ & $C_{2}$ & $\sigma^{\mathrm{b}}$ & $A A D^{\mathrm{c}}(\%)$ \\
\hline \multicolumn{8}{|l|}{ Water $+n$-butyl acetate } \\
\hline$V_{12}^{\mathrm{E}}\left(\mathrm{cm}^{3} \cdot \mathrm{mol}^{-1}\right)$ & -0.235 & & & 0.959 & & 0.002 & 2.2 \\
\hline$G_{12}^{\neq \mathrm{E}}(\mathrm{mPa} \cdot \mathrm{s})^{\mathrm{a}}$ & 1705.3 & -892.4 & & & & 0.000 & 0.0 \\
\hline$\eta_{12}(\mathrm{mPa} \cdot \mathrm{s})$ & -0.656 & -0.596 & & & & 0.000 & 4.7 \\
\hline$\gamma_{12}\left(\mathrm{mN} \cdot \mathrm{m}^{-1}\right)$ & -149.935 & -127.338 & & & & 0.05 & 5.1 \\
\hline \multicolumn{8}{|l|}{ Water+1-propanol } \\
\hline$V_{13}^{\mathrm{E}}\left(\mathrm{cm}^{3} \cdot \mathrm{mol}^{-1}\right)$ & -2.495 & & & -0.246 & -0.382 & 0.006 & 1.0 \\
\hline$G_{13}^{7 \mathrm{E}}(\mathrm{mPa} \cdot \mathrm{s})^{\mathrm{a}}$ & 8321.2 & & & -0.861 & 0.063 & 0.013 & 0.6 \\
\hline$\eta_{13}(\mathrm{mPa} \cdot \mathrm{s})$ & 3.540 & & & -1.120 & 0.398 & 0.018 & 3.1 \\
\hline$\gamma_{13}\left(\mathrm{mN} \cdot \mathrm{m}^{-1}\right)$ & -80.14 & & & -1.152 & 20.185 & 0.83 & 3.3 \\
\hline \multicolumn{8}{|c|}{$n$-Butyl acetate +1 -propanol } \\
\hline$V_{23}^{\mathrm{E}}\left(\mathrm{cm}^{3} \cdot \mathrm{mol}^{-1}\right)$ & 0.696 & 0.207 & -0.303 & & & 0.007 & 3.9 \\
\hline$G_{23}^{\not \mathrm{E}}(\mathrm{mPa} \cdot \mathrm{s})^{\mathrm{a}}$ & -2933.3 & & & 0.431 & -0.062 & 0.002 & 0.2 \\
\hline$\eta_{23}(\mathrm{mPa} \cdot \mathrm{s})$ & -1.719 & & & 0.626 & $5-0.030$ & 0.002 & 0.5 \\
\hline$\gamma_{23}\left(\mathrm{mN} \cdot \mathrm{m}^{-1}\right)$ & 1.741 & & & 0.039 & -0.075 & 0.00 & 0.4 \\
\hline \multicolumn{8}{|c|}{ Water $+n$-butyl acetate +1 -propanol } \\
\hline$V_{123}^{\mathrm{E}}\left(\mathrm{cm}^{3} \cdot \mathrm{mol}^{-1}\right)$ & -1.813 & -2.915 & -1.97 & & & 0.005 & 2.3 \\
\hline$G_{123}^{\not \mathrm{E}}(\mathrm{mPa} \cdot \mathrm{s})^{\mathrm{d}}$ & -903.4 & 10160.7 & -3892.6 & & & 0.026 & 1.7 \\
\hline$\eta_{123}(\mathrm{mPa} \cdot \mathrm{s})$ & -6.348 & -5.825 & 10.203 & & & 0.023 & 8.7 \\
\hline$\gamma_{123}\left(\mathrm{mN} \cdot \mathrm{m}^{-1}\right)$ & 246.735 & 53.475 & & -1.369 & & 0.74 & 9.0 \\
\hline
\end{tabular}

${ }^{\mathrm{a}} G_{i j}^{\neq \mathrm{E}}$ was defined by Eq. 5 and is used in Eq. 4 for $\eta$

b Standard deviation, Eq. 24, given in the units of the respective quantity

c Average absolute deviation, Eq. 25

${ }^{\mathrm{d}} G_{123}^{\neq \mathrm{E}}$ was defined by Eq. 10
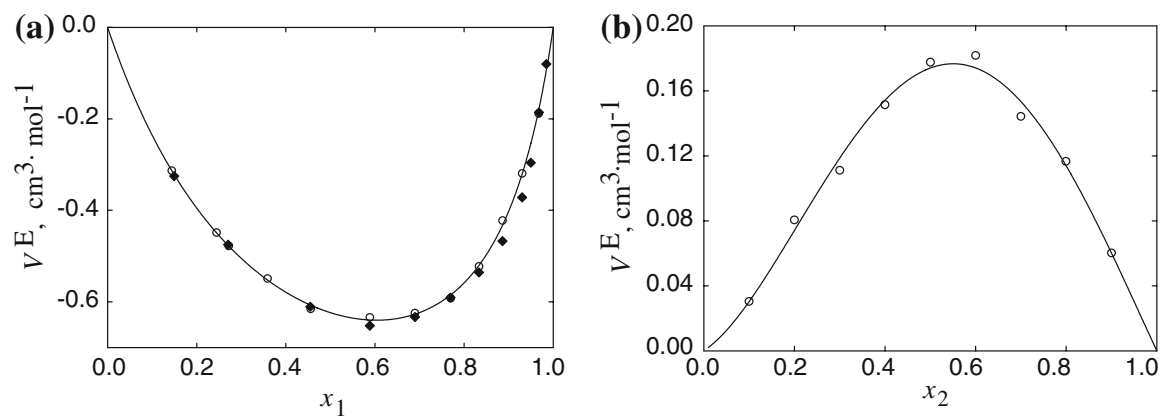

Fig. 1 Excess molar volume, $V^{\mathrm{E}}$, of the binary systems at $303.15 \mathrm{~K}$ as a function of the mole fractions: (a) water (1) + 1-propanol (3); (b) $n$-butyl acetate (2) + 1-propanol (3). Symbols refer to experimental data: (o) this work; ( ) Mikhail and Kimel [29]. Curves were calculated with Eq.5

and ester, respectively. It can be seen from Fig. 1a that our data for the water + 1-propanol system are in good agreement with the values of Mikhail and Kimel [29]. The minimum value of the excess molar volume is $V^{\mathrm{E}}\left(x_{1}=0.60\right)=-0.64 \mathrm{~cm}^{3} \cdot \mathrm{mol}^{-1}$. For the $n$-butyl acetate +1 -propanol system, no data have been found in the literature. 

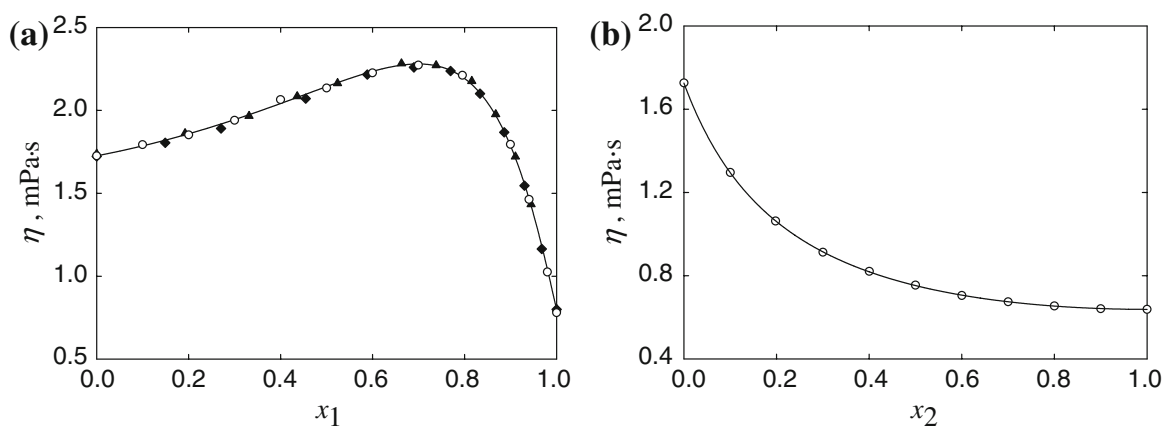

Fig. 2 Viscosity, $\eta$, of the binary systems at $303.15 \mathrm{~K}$ as a function of the mole fractions: (a) water (1)+ 1-propanol (3); (b) $n$-butyl acetate (2) + 1-propanol (3). Symbols refer to experimental data: (o) this work; ( ) Mikhail and Kimel [29]; ( $\mathbf{\Delta})$ Dizechi and Marschall [30]. Curves of (a) and (b) were calculated with the correlation of the excess Gibbs energy of activation of viscous flow, Eq. 5, applied to Eq. 4

Table 6 Coefficients, standard deviations, $\sigma$, and average absolute deviations, $A A D$, of viscosity correlation models

\begin{tabular}{lll}
\hline System & Noda-Ishida & UNIMOD \\
\hline $\begin{array}{l}\text { Water }+n \text {-butyl acetate } \\
\sigma(\mathrm{mPa} \cdot \mathrm{s})\end{array}$ & 0.000 & \\
$A A D(\%)$ & 0.02 & 0.001 \\
Parameters & $w_{12}=-0.057$ & 0.1 \\
& $w_{21}=0.601$ & $U_{21}-U_{11}=125.93$ \\
Water +1 -propanol & & $U_{12}-U_{22}=517.19$ \\
$\sigma(\mathrm{mPa} \cdot \mathrm{s})$ & 0.013 & \\
$A A D(\%)$ & 0.6 & 0.017 \\
Parameters & $w_{13}=2.100$ & 0.7 \\
& $w_{31}=-0.633$ & $U_{31}-U_{11}=552.17$ \\
$n$-Butyl acetate + 1-propanol & 0.035 & $U_{13}-U_{33}=241.75$ \\
$\sigma(\mathrm{mPa} \cdot \mathrm{s})$ & 3.0 & 0.005 \\
$A A D(\%)$ & $w_{23}=-1.680$ & 0.5 \\
Parameters & $w_{32}=-1.020$ & $U_{32}-U_{22}=-159.82$ \\
Water $+n$-butyl acetate +1 -propanol & & $U_{23}-U_{33}=33.21$ \\
$\sigma(\mathrm{mPa} \cdot \mathrm{s})$ & 0.326 & 0.268 \\
$A A D(\%)$ & 16.7 & 19.5 \\
\hline
\end{tabular}

a The standard deviation and the $A A D$ were calculated in terms of the dynamic viscosity

The experimental and fitted values of $\eta$ for the binary systems, water +1 -propanol and $n$-butyl acetate +1 -propanol, as a function of the compositions of water and ester are compared in Fig. 2. In this figure we have also plotted the values taken from the literature, which are in excellent agreement with our data.

The results obtained by the application of the Noda-Ishida and UNIMOD models are presented in Table 6. For the correlation of the binary viscosity, the best results were obtained with the UNIMOD model. For the ternary mixtures, the predictions of the two models are similar.

In Fig. 3 we have plotted the experimental and fitted surface tensions of the binary systems of water +1 -propanol and $n$-butyl acetate +1 -propanol as a function of the 

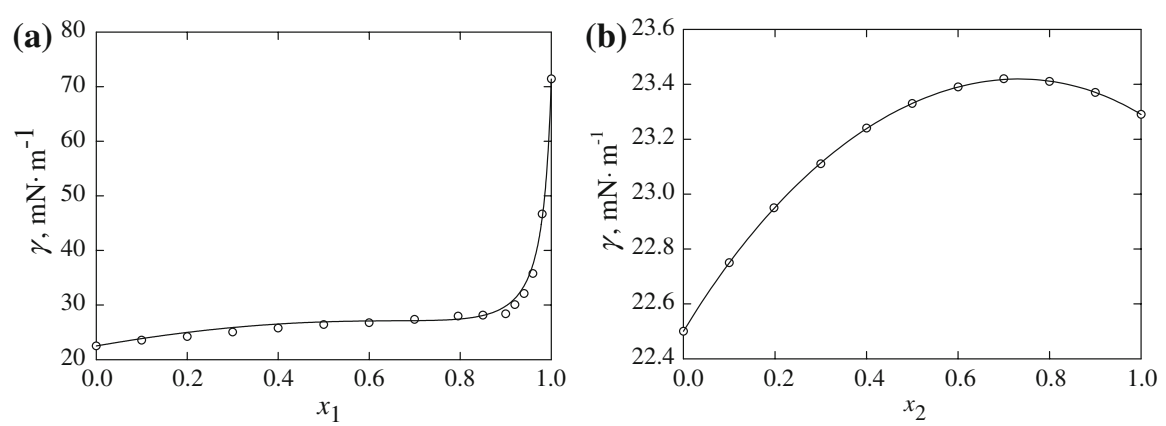

Fig. 3 Surface tension, $\gamma$, for the binary systems: (a) water (1) +1-propanol (3) and (b) $n$-butyl acetate (2) + 1-propanol (3) at 303.15 K, as a function of the composition. Symbols correspond to the experimental data of this work, and the curve represents the correlation with Eq. 6

Table 7 Parameters of the correlation models of Fu et al. and $\mathrm{Li}$ etal. for the surface tension of binary systems

\begin{tabular}{lll}
\hline System & Fu et al. & Li etal. \\
\hline Water $+n$-butyl acetate & & \\
$\sigma\left(\mathrm{mN} \cdot \mathrm{m}^{-1}\right)$ & 0.11 & 0.11 \\
$A A D(\%)$ & 0.3 & 0.3 \\
Parameters & $f_{12}=1.529$ & $\Lambda_{21}=5.240 \times 10^{-2}$ \\
& $f_{21}=-0.014$ & $\left(\frac{\partial \Lambda_{21}}{\partial A}\right)_{T, P, x}=-6.949 \times 10^{-7}$ \\
Water +1 -propanol & & \\
$\sigma\left(\mathrm{mN} \cdot \mathrm{m}^{-1}\right)$ & 2.09 & 1.56 \\
$A A D(\%)$ & 6.4 & 4.3 \\
Parameters & $f_{13}=16.390$ & $\Lambda_{31}=1.340 \times 10^{-2}$ \\
& $f_{31}=0.014$ & $\left(\frac{\partial \Lambda_{31}}{\partial A}\right)_{T, P, x}=-2.369 \times 10^{-7}$ \\
$n$-Butyl acetate +1 -propanol & & \\
$\sigma\left(\mathrm{mN} \cdot \mathrm{m}^{-1}\right)$ & 0.01 & 0.01 \\
$A A D(\%)$ & 0.02 & 0.04 \\
Parameters & $f_{23}=0.908$ & $\Lambda_{32}=9.206 \times 10^{-1}$ \\
& $f_{32}=0.985$ & $\left(\frac{\partial \Lambda_{32}}{\partial A}\right)_{T, P, x}=7.781 \times 10^{-6}$ \\
Water $+n$-butyl acetate & & \\
+1 -propanol & & 0.77 \\
$\sigma\left(\mathrm{mN} \cdot \mathrm{m}^{-1}\right)$ & 0.82 & 2.3 \\
$A A D(\%)$ & 2.2 & \\
\hline
\end{tabular}

Results of the prediction of ternary system due to these models

composition. From Table 5 we can see that the larger standard deviation occurs in the water + 1-propanol binary where the values of the surface tension present a behavior difficult to describe, as can be seen in Fig. 3a. Figures 1-3 stress the correlating ability of the Myers and Scott rational equation.

The ability of the methods of $\mathrm{Li}$ etal. [14] and $\mathrm{Fu}$ etal. [13] to correlate the binary surface tension data and to predict the ternary system can be judged from Table 7. The surface tension of the ternary systems was well predicted using these models. 


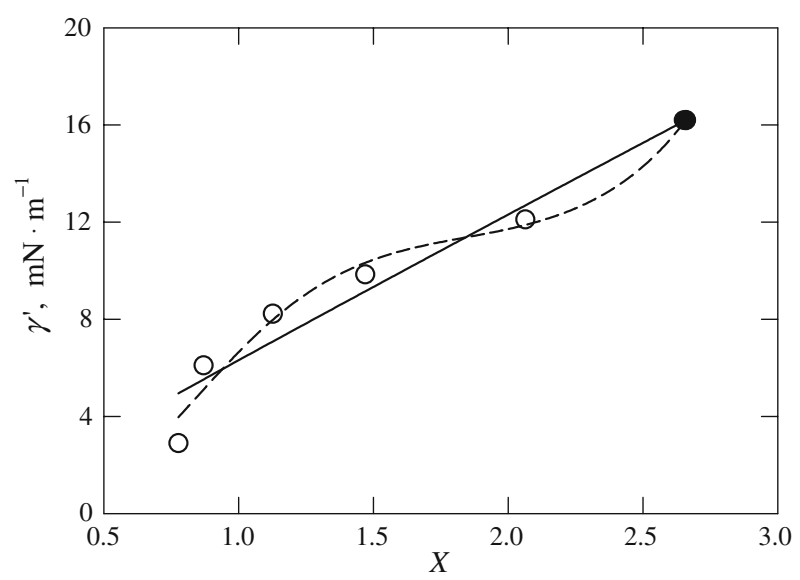

Fig. 4 Liquid interfacial tension, $\gamma^{\prime}$, as a function of $X$ for the ternary water $(1)+n$-butyl acetate (2)+ 1-propanol (3) system. Symbols (•) and (o) represent the experimental data of the binary and ternary system, respectively, and the lines represent the fits with the $\mathrm{Li}$ and $\mathrm{Fu}[15]$ model, Eq. 22: (-) $k=$ constant and (- -) $k=k_{0}+k_{1} X+k_{2} X^{2}$

The results for the fitting of the $\mathrm{Li}$ and $\mathrm{Fu}$ model, Eq. 22, to the liquid interfacial tension, $\gamma^{\prime}$, are represented in Fig. 4. A good representation of the experimental data is obtained taking into consideration a quadratic dependence of the composition, with $k_{0}=2.757, k_{1}=-2.882$, and $k_{2}=1.056$. The same conclusion was already reported in previous work [4].

\section{References}

1. S.L. Oswal, S.S.R. Putta, Thermochim. Acta 373, 141 (2001)

2. M.L. Kijevcanin, I.S.A. Ribeiro, A.G.M. Ferreira, I.M.A. Fonseca, J. Chem. Eng. Data 48, 1266 (2003)

3. F. Giro, M.F. Gonçalves, A.G.M Ferreira, I.M.A. Fonseca, Fluid Phase Equilib. 204, 217 (2003)

4. B.M.S. Santos, A.G.M. Ferreira, I.M.A. Fonseca, Fluid Phase Equilib. 208, 1 (2003)

5. M.L. Kijevcanin, I.S.A. Ribeiro, A.G.M. Ferreira, I.M.A. Fonseca, Fluid Phase Equilib. 218, 141 (2004)

6. R.L. Gardas, I. Johnson, D.M.D. Vaz, I.M.A. Fonseca, A.G.M. Ferreira, J. Chem. Eng. Data 52, 735 (2007)

7. D.B. Myers, R.L. Scott, Ind. Eng. Chem. 55, 43 (1963)

8. C. Pando, J.A.R. Renuncio, J.A.G. Calzon, J.J. Christensen, R.M. Izatt, J. Solution Chem. 16, 503 (1987)

9. R.E. Powell, W.E. Roseveare, H. Eyring, Ind. Eng. Chem. 33, 430 (1941)

10. K. Noda, K. Ishida, J. Chem. Eng. Japan 10, 478 (1977)

11. W. Cao, A. Fredenslund, P. Rasmussen, Ind. Eng. Chem. Res. 31, 2603 (1992)

12. W. Cao, K. Knudsen, A. Fredenslund, P. Rasmussen, Ind. Eng. Chem. Res. 32, 2077 (1993)

13. J. Fu, B. Li, Z. Wang, Chem. Eng. Sci. 41, 2673 (1986)

14. C. Li, W. Wang, Z. Wang, Fluid Phase Equilib. 175, 185 (2000)

15. B. Li, J. Fu, J. Chem. Eng. Data 37, 172 (1992)

16. H. Sato, M. Vematsu, K. Watanabe, J. Phys. Chem. Ref. Data 17, 1439 (1988)

17. C.Y. Liu, H.C. Ku, C.H. Tu, J. Chem. Eng. Data 44, 360 (1999)

18. N.G. Tsierkezos, A.E. Kelarakis, M.M. Palaiologou, J. Chem. Eng. Data 45, 395 (2000)

19. Z.P. Visak, A.G.M. Ferreira, I.A.M. Fonseca, J. Chem. Eng. Data 45, 926 (2000)

20. N.A.T. Natividade, A.G.M. Ferreira, I.M.A. Fonseca, J. Chem. Eng. Data 42, 1232 (1997)

21. J.L. Hales, J.H. Ellender, J. Chem. Thermodyn. 8, 1177 (1976) 
22. L. Pikkarainen, J. Chem. Eng. Data 28, 344 (1983)

23. J. Kestin, M. Sokolov, A. Wakeham, J. Phys. Chem. Ref. Data 7, 941 (1978)

24. J.A. Riddick, W.B. Bunger, T.K. Sakano. Organic Solvents. Physical Properties and Methods of Purification, Techniques of Chemistry, vol. II, 3rd edn. (Wiley, New York, 1986)

25. M.A Saleh, M. Habibullah, M.S. Ahmed, M.A. Uddin, S.M.H. Uddin, M.A. Uddin. F.M. Khan, Phys. Chem. Liquids 44, 31 (2006)

26. J.J. Jasper, J. Phys. Chem. Ref. Data 1, 841 (1972)

27. R.J. Rao. C.V. Rao, J. Appl. Chem. 9, 69 (1959)

28. S. Skjold-Jørgensen, P. Rasmussen, Aa. Fredenslund, Chem. Eng. Sci. 35, 2389 (1980)

29. S.Z. Mikhail, W.R. Kimel, J. Chem. Eng. Data 8, 323 (1963)

30. M. Dizechi, E. Marschall, J. Chem. Eng. Data 27, 358 (1982) 